\title{
PENGARAHAN DAN PENYERAHAN BANTUAN PEMBUATAN PERAHU TINGTING SERTA PENGHIBURAN ANAK-ANAK KORBAN TSUNAMI DI DESA BANYUASIH, PANDEGLANG PROVINSI BANTEN
}

\author{
Chatarina Niken* \\ Jurusan Teknik Sipil Universitas Lampung, Bandar Lampung \\ Jl. Prof. Sumantri Brojonegoro No.1 Bandar Lampung 35145 \\ Penulis Korespodensi : chatarinaniken@yahoo.com
}

\begin{abstract}
Abstrak
Pada tanggal 22 Desember 2018, terjadi tsunami akibat erupsi gunung Anak Krakatau di daerah pesisir Banten dan Lampung. Terdapat lima kabupaten yang mengalami kerusakan, yaitu Pandeglang, Serang, Lampung Selatan, Pesawaran, dan Tanggamus. Sampai 31-12-2018, dinyatakan 437 jiwa meninggal dunia 14.059 orang mengalami luka-luka, 16 orang hilang, dan 33.721 mengungsi. Bangunan rusak di antaranya 2.752 rumah dan 92 penginapan atau warung. Alat transportasi sebanyak 510 perahu dan kapal, 147 kendaraan, serta dua fasilitas dermaga dan shelter juga mengalami kerusakan. Pandeglang adalah wilayah terparah. Jarak antara Gunung Anak Krakatau dan Kabupaten Pandeglang sekitar $65 \mathrm{~km}$. Dengan jarak tersebut jumlah orang tewas Pandeglang terbanyak yaitu 296 meninggal. Kebanyakan adalah wisatawan pengunjung. Korban lain adalah 7.656 orang terluka, 8 orang hilang, dan 20.726 orang mengungsi. Desa Banyuasih, adalah sebuah Desa di Kabupaten Pandeglang, terletak di pesisir Laut Jawa. Trauma pada orang dewasa dapat dipulihkan dengan mengembalikan ke kegiatan sehari-hari sebelum musibah menimpa. Berdasarkan hal ini maka dipilih pemberian perahu ting-ting, agar mereka kembali melaut sehingga memperoleh rezeki sekaligus menghilangkan trauma sedikit demi sedikit. Penghilangan trauma pada nak-anak dilakukan dengan mengajak berdiskusi, menyanyi dan mendongeng. Dari wawancara diperoleh tanggapan bahwa mereka senang karena merasa diperhatikan.
\end{abstract}

Kata kunci: Anak Krakatau, Pandeglang, Perahu ting-ting, Trauma, Tsunami

\section{Pendahuluan}

Pada tanggal 22 Desember 2018, terjadi tsunami akibat erupsi gunung Anak Krakatau di daerah pesisir Banten dan Lampung (Dwi Korita, 2018; Sutopo, 2018. Terdapat lima kabupaten yang mengalami kerusakan, yaitu Pandeglang, Serang, Lampung Selatan, Pesawaran, dan Tanggamus. Sampai 31-12-2018, dinyatakan 437 jiwa meninggal dunia 14.059 orang mengalami luka-luka, 16 orang hilang, dan 33.721 mengungsi. Bangunan rusak di antaranya 2.752 rumah dan 92 penginapan atau warung. Alat transportasi sebanyak 510 perahu dan kapal, 147 kendaraan, serta dua fasilitas dermaga dan shelter juga mengalami kerusakan (Kepala Desa Banyuasih, 2019).

Pandeglang adalah wilayah terparah. Jarak antara Gunung Anak Krakatau dan Kabupaten Pandeglang sekitar $65 \mathrm{~km}$. Dengan jarak tersebut jumlah orang tewas Pandeglang terbanyak yaitu 296 meninggal. Kebanyakan adalah wisatawan pengunjung. Korban lain adalah 7.656 orang terluka, 8 orang hilang, dan 20.726 orang mengungsi (Sutopo, 2018). Desa Banyuasih, adalah sebuah Desa di Kabupaten Pandeglang, terletak di pesisir seperti Gambar 1.

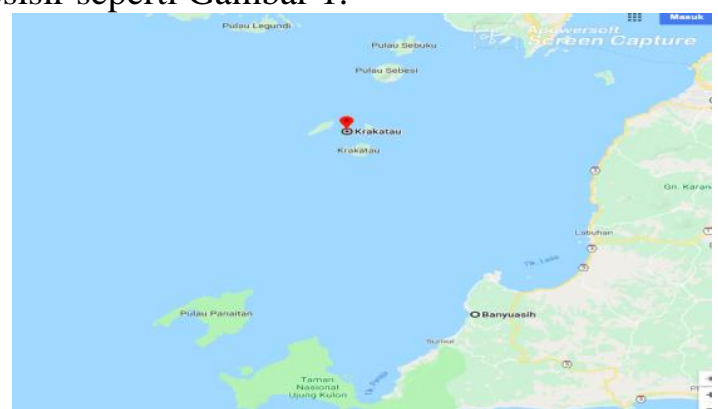

Gambar 1. Lokasi Gunung Anak Krakatau dan Desa Banyuasih, Pandeglang Banten

Luas Desa Banyuasih \pm 4234 ha dengan jumlah Kepala Keluarga (KK) \pm 1500 . Jumlah penduduk sekitar 4500 orang. Kepala keluarga yang mengandalkan hidup sebagai nelayan ada $500 \mathrm{KK}$. 
Dari kejadian tsunami tanggal 22 Desember 2018 kerusakkan di Desa Banyuasih adalah:

Perahu tingting

Bagang apung

Perahu sampan

Gilingan padi

Perahu motor

Warung sembako

Secara rinci tingkat kerusakan dengan foto kerusakan tertera pada Gambar 2.

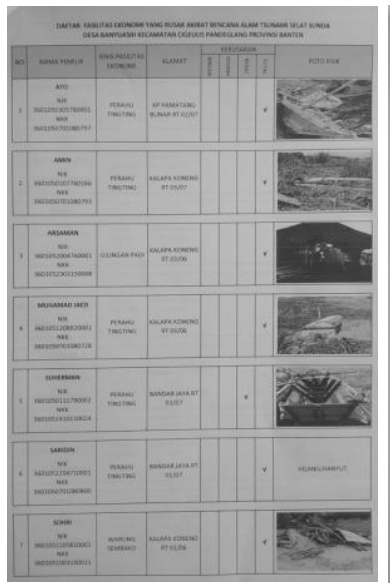

(a)

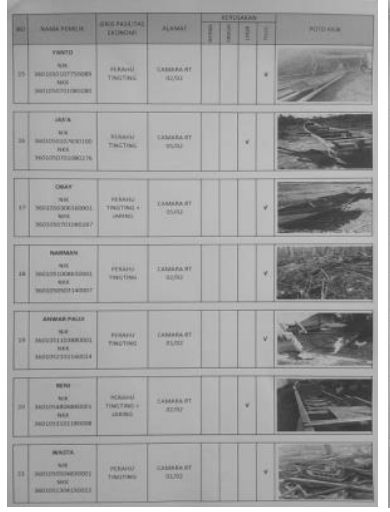

(c)

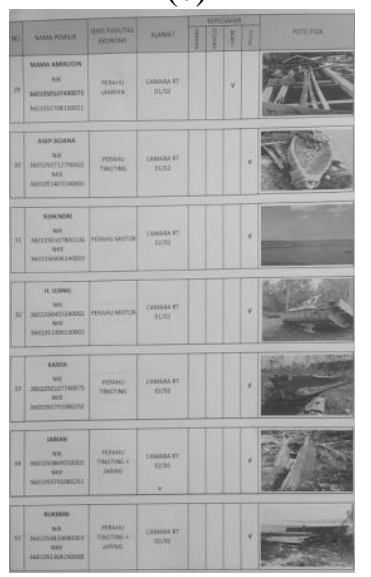

(e)

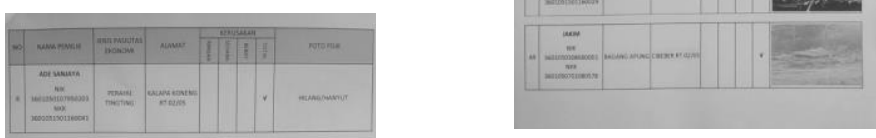

(g)

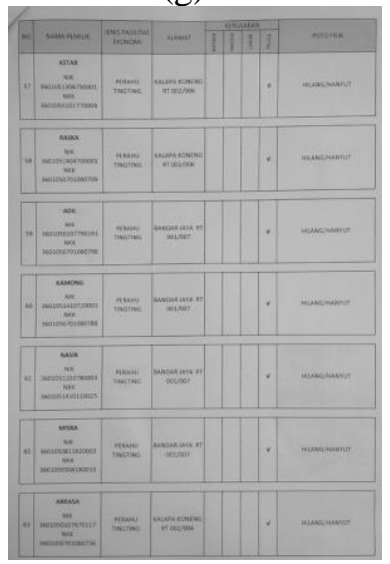

(j)

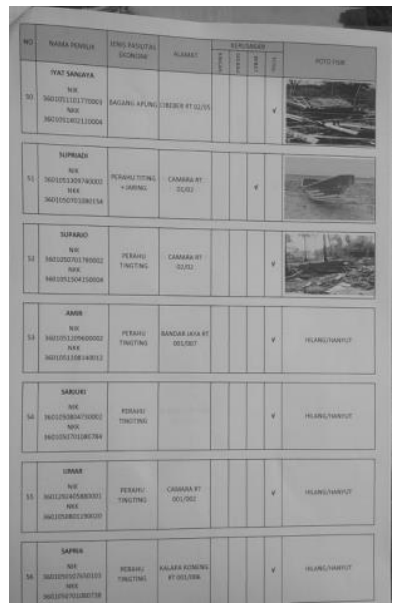

(h)

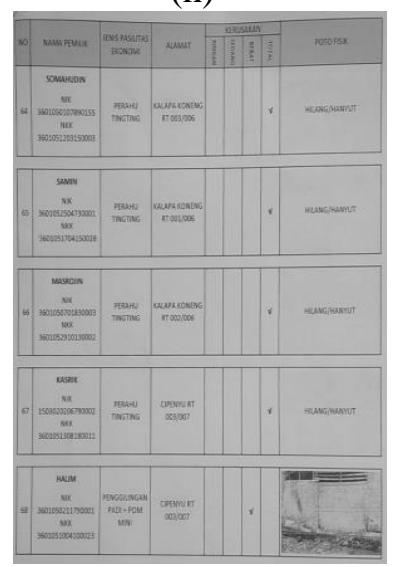

(k)

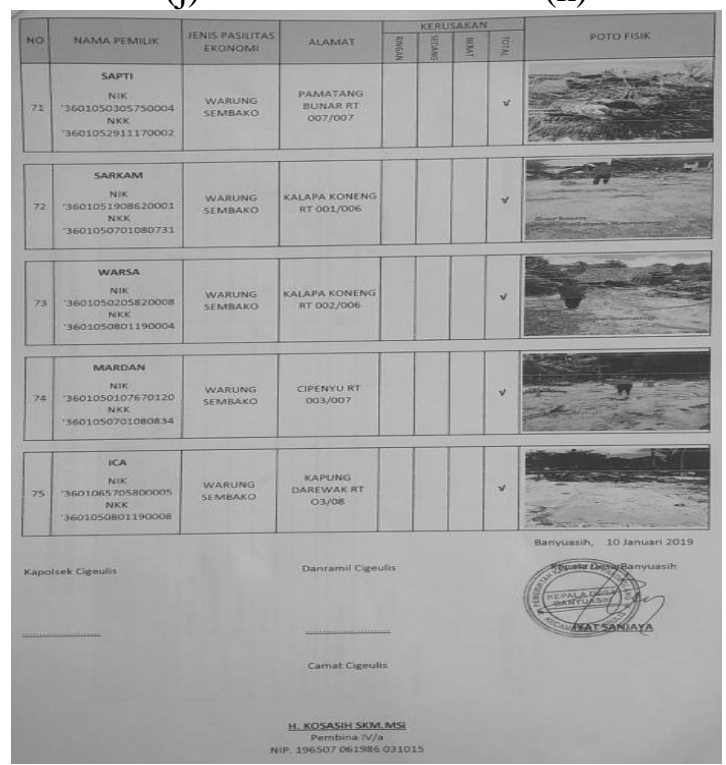

(1)
Gambar 2. Kerusakan perahu, bagang, dan warung

Data tersebut kami peroleh dari Sekretaris Kelurahan Desa Banyuasih (Gambar 3). 


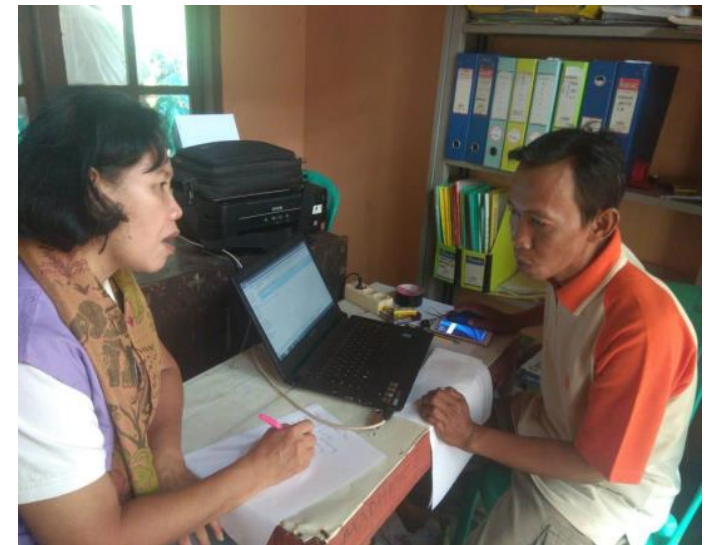

Gambar 3. Wawancara dengan Sekretaris Kelurahan Desa Banyuasih

Agar masyarakat dapat segera mendapatkan penghasilan, kami memandang bahwa bantuan yang paling dibutuhkan adalah perahu tingting. Selain untuk mendapat penghasilan, cara untuk menghilangkan trauma adalah kembali ke aktivitas semula (Dosen Psikologi, 2017; Yayasan Pulih, 2004). Beberapa warga Desa memiliki kemampuan untuk membuat perahu tingting. Gambaran perahu tingting disajikan pada Gambar 4.

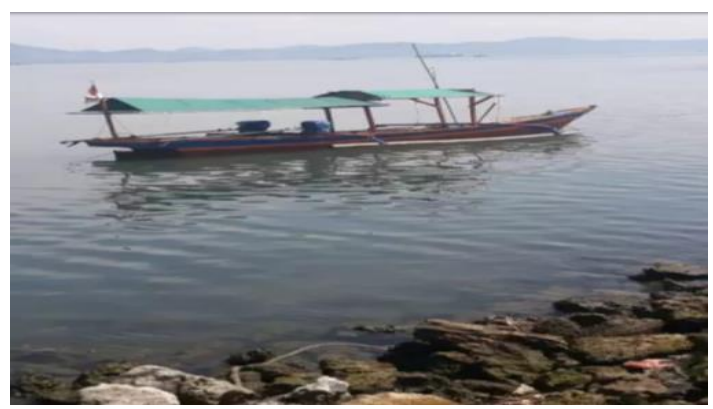

Gambar 4. Perahu tingting

Untuk membuat 1 buah perahu tingting diperlukan waktu sekitar 2 bulan. Satu (1) perahu dapat memuat 2 - 3 orang KK, sehingga apabila dipakai sehari 2 shift maka satu perahu dapat untuk 4 - 6 KK. Perahu tingting dapat terbuat dari kayu. Papan terbuat dari kayu bungur dan mahoni, tulang perahu dari kayu bungur dan labang, sedang pengaku memanjang dari kayu salam, cherry atau mangga. Harga 1 perahu tingting ditaksir Rp13.500.000,00

Sebagian anak - anak Desa Banyuasih mengalami trauma ketakutan bila mendengar suara gemuruh. Jumlah anak - anak dari yang belum sekolah sampai Sekolah Dasar berkisar 150 orang. Untuk meringankan trauma tersebut kami membuat acara penghiburan, menyanyi, mendongeng, bermain, dan mewarnai (Nindias, 2018).
Tujuan dan Manfaat

Tujuan pengabdian masyarakat ini adalah:

- Memberi pengarahan dalam penerimaan bantuan pembuatan perahu tingting

- Memberikan terapi kepada anak - anak yang mengalami trauma ketakutan karena tsunami

Manfaat pengabdian masyarakat ini adalah:

1. Adanya lapangan pekerjaan yaitu membuat perahu tingting kayu

2. Adanya kemampuan untuk mengolah uang bantuan

Adanya penyembuhan trauma ketakutan bagi anak - anak korban tsunami

\section{Metode Pengabdian pada Masyarakat}

Metode yang dipakai dalam pengabdian masyarakat ini adalah:

1. Mencari donatur pengadaan perahu tingting

2. Memberikan pengarahan dalam mengelola bantuan agar dapat bergulir

3. Memonitor pelaksanaan pembuatan perahu tingting

4. Memberikan penghiburan kepada anak - anak berupa: bernyanyi, mendengarkan dongeng, mewarnai dengan lomba dan bermain

\section{Kegiatan dan Hasil}

Kegiatan pengabdian masyarakat dibagi menjadi dua bagian yaitu pengarahan pemberian bantuan perahu tingting, penghiburan untuk anakanak korban tsunami dan pemantauan pembuatan perahu tingting.

\section{A. Pengarahan Pemberian Bantuan Pembuatan Perahu Tingting}

Berdasarkan survey pendahuluan yang dilakukan pada Bulan Januari 2019, dilakukan pencarian donatur. Sampai awal bulan Maret 2019 terkumpul uang untuk pembuatan 14 buah perahu tingting. Setelah dicapai kesepakatan pengelolaan uang dan perahu oleh kami, Lurah, BUMDES dan masyarakat, kami mengadakan kunjungan ini untuk memberi pengarahan kepada para penerima bantuan sekaligus mengadakan penghiburan sebagai terapi trauma ketakutan bagi anak-anak korban tsunami. Lama perjalanan dari Jakarta berkisar 6 jam dengan jalan yang berbelok - belok, naik dan turun sehingga perut seperti terkocok. Sebagian jalan kira - kira $3 \mathrm{~km}$ rusak parah. 
Kondisi fisik kantor Kepala Desa cukup baik (Gambar 5).

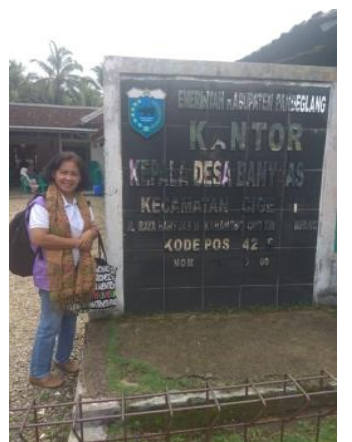

Gambar 5. Kantor Kepala Desa Banyuasih

Kegiatan pengarahan bagi para nelayan dilakukan di jalan yang terletak di depan Kantor Kepala Desa. Suasana pengarahan dapat dilihat pada Gambar 6.

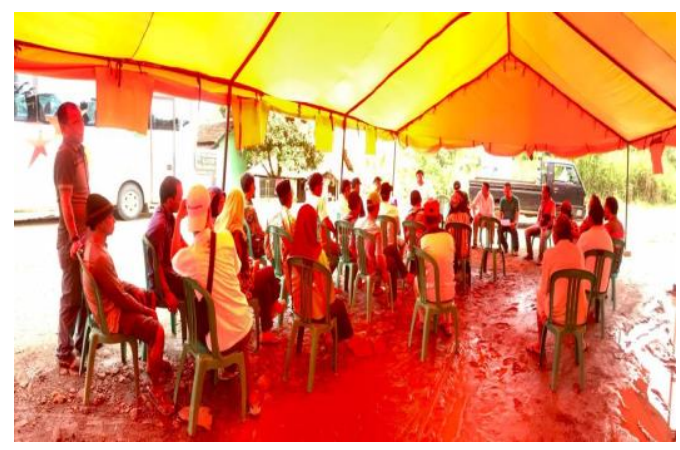

Gambar 6. Pengarahan pengelolaan bantuan pembuatan perahu

Bantuan dari donator diberikan dalam bentuk uang untuk pembuatan 14 perahu. Uang akan dikelola oleh BUMDES (Badan Usaha Milik Desa). Telah diutarakan sebelumnya bahwa perahu tingting yang rusak 53 buah, sehingga perlu kerjasama dan tanggung jawab yang jelas dari setiap Nelayan. Karena keterbatasan tersebut tidak semua Nelayan mendapat jatah perahu, namun mendapat jatah menggunakan perahu. Dari pengalaman para Nelayan, perahu tingting dapat memuat 1.5 kwintal ikan. Kalau ditangkap oleh 3 Nelayan, maka masing - masing mendapatkan 50 $\mathrm{kg}$ ikan, bila diambil harga murah Rp10.000,00 per $\mathrm{kg}$, maka setiap Nelayan memperoleh hasil kotor Rp500.000,00 untuk sekali melaut. Dari penghasilan tersebut setiap Nelayan wajib menyetorkan $10 \%$ kepada BUMDES. Uang tersebut digunakan untuk perawatan, perbaikan dan juga pembuatan perahu lagi.

\section{B. Penghiburan bagi Anak-anak Korban Tsunami}

Kegiatan bagi anak - anak dilakukan di balai desa yang sebenarnya hanya berkapasitas 40 orang, namun saat kegiatan terisi oleh \pm 165 orang karena beberapa anak tidak bisa terlepas dari ibunya (Gambar 7a). Kegiatan mewarnai membuat anak anak aktif mengeluarkan kemampuannya dan kreatifitasnya (Gambar 7b). Diharapkan kegiatan ini dapat mengurangi trauma mereka akibat tsunami.

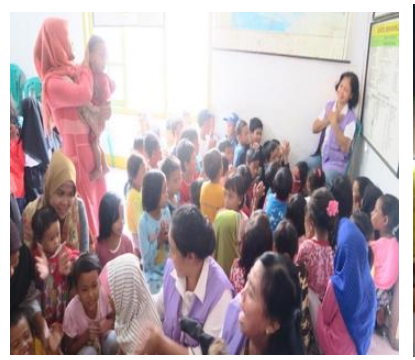

(a)

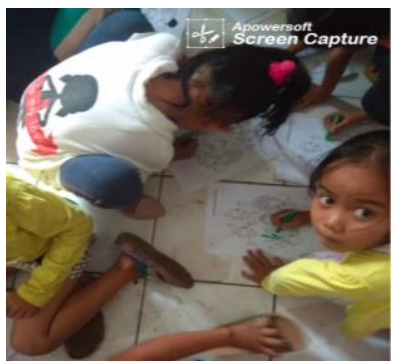

(b)
Gambar 7. Kegiatan anak - anak:

(a) Mendengarkan dongeng, (b) Mewarnai

\section{Pemantauan Pembuatan Perahu Tingting}

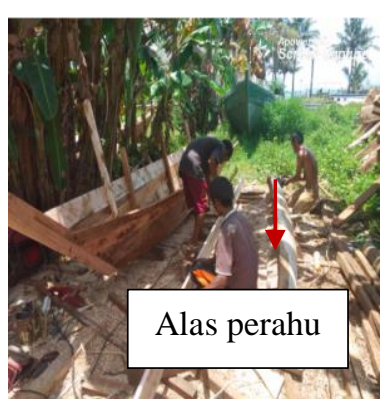

(a)

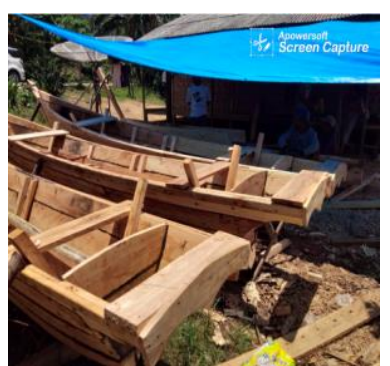

(c)

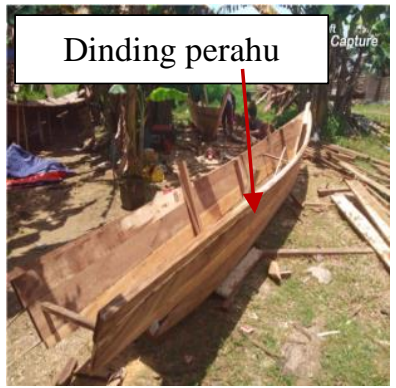

(b)

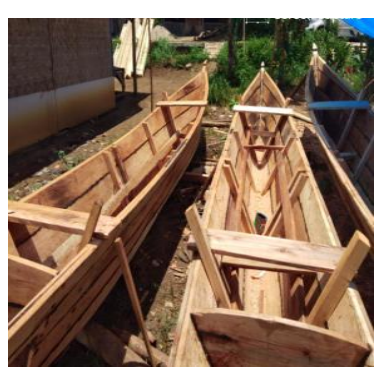

(d)
Gambar 8. (a) Pembuatan alas perahu, (b) Pembuatan dinding perahu, (c) Setengah perahu, (d) Perahu dengan badan dan dinding

Pemantauan sebelum waktu selesainya perahu dilakukan melalui Lurah, BUMDES dan masyarakat dengan memakai teknologi komunikasi Whatshapp yang telah masuk sampai daerah tersebut setiap minggu. Sampai tanggal 9 Maret 
2019, kemajuan pembuatan perahu dapat dilihat pada Gambar 8a, 8b, 8c, dan 8d.

\section{Kesimpulan}

Kegiatan ini membuat Lurah merasa penderitaan warganya diperhatikan oleh saudara sebangsa meskipun tempat tinggalnya jauh. Bantuan perahu tingting ini tidak mencukupi kebutuhan semua warga Nelayan yang perahunya rusak, sehingga perlu ada system penyetoran sebagian hasil tangkapan kepada BUMDES yang dipergunakan untuk perawatan dan perbaikan perahu serta pembuatan perahu, sehingga semua Nelayan bisa memiliki perahu. Rasa adil, iklas dan bersyukur perlu ditanamkan bagi semua warga, sehingga hal-hal negatif yang mungkin muncul dapat dihindari. Pemberian bantuan ini perlu dimonitor pada saat: perahu mulai jadi dan saat perahu mulai dioperasikan. Administrasi pembelanjaan, administrasi penyetoran sebagian hasil, dan penggunaan dana perlu diarahkan dan dipantau.

Terapi trauma bencana tsunami berupa penghiburan, sekaligus dapat dilaksanakan bersama pemonitoran pembangunan, pengoperasian dan administrasi uang bantuan.

\section{Ucapan Terima Kasih}

Terima kasih disampaikan kepada LPPM UNILA yang telah mendanai keberlangsungan jurnal ini. Terima kasih disampaikan kepada Afri Yudamson yang telah meluangkan waktu untuk membuat template ini. Terima kasih yang mendalam saya sampaikan kepada para Donatur dan Prana Indonesia.

\section{Daftar Pustaka}

Dosen Psikologi. (2017). 20 Cara Menghilangkan Trauma pada Anak yang Efektif, dosenpsikologi.com

Dwikorita. (2018). Kronologi Tsunami di Banten. BMKG,http://nasional.kompas.com

Kepala Desa Banyu Asih Pandeglang Banten. (2019). Surat Pernyataan. No 400/. /DS2007/SP/I/2019.

Nindias N.K. (2018). Dalam Tirto.id. Apa saja Tahap Trauma Healing Pasca Bencana? Menggambar sebagai salah satu Trauma Healing. https://tirto.id/apa-saja-tahap-trauma-healingpasca-bencana-cRoq.

Sutopo, P. N. (2018). Klarifikasi BNPB, https://nasional.kompas.com

Yayasan Pulih. (2004) dalam Tirto.id. Apa saja Tahap Trauma Healing Pasca Bencana? https://tirto.id/apa-saja-tahap-trauma-healingpasca-bencana-cRoq. 